Gut and Liver, Vol. 10, No. 5, September 2016, pp. 826-835

\title{
NADPH Oxidase 1 and NADPH Oxidase 4 Have Opposite Prognostic Effects for Patients with Hepatocellular Carcinoma after Hepatectomy
}

\author{
Sang Yun $\mathrm{Ha}^{1}$, Yong-Han Paik ${ }^{2}$, Jung Wook Yang ${ }^{1}$, Min Ju Lee ${ }^{1}$, Hyunsik Bae ${ }^{1}$, and Cheol-Keun Park ${ }^{1}$ \\ Departments of ${ }^{1}$ Pathology and ${ }^{2}$ Medicine, Samsung Medical Center, Sungkyunkwan University School of Medicine, Seoul, Korea
}

Background/Aims: Nicotinamide adenine dinucleotide phosphate oxidase (NOX)-mediated reactive oxygen species contribute to various liver diseases, including hepatocellular carcinoma (HCC). Uncertainties remain regarding the prognostic relevance of NOX1 and NOX4 protein expression in HCC. Methods: NOX1 and NOX4 protein expression was examined by using immunohistochemistry in tumor tissue from 227 HCC patients who underwent hepatectomy. Results: High immunoreactivity for NOX1 was observed in 197 (86.8\%) of the 227 HCC cases and low immunoreactivity for NOX4 in 112 (49.3\%). NOX1 and NOX4 proteins had opposite prognostic effects. High NOX1 expression was an independent predictor of both shorter recurrence-free survival (RFS) $(p<0.01)$ and shorter overall survival $(0 S)$ $(p=0.01)$. Low NOX4 expression was an independent predictor of both shorter RFS $(p<0.01)$ and shorter OS $(p=0.01)$. Subgroup analysis showed that, among patients with normal $\alpha$-fetoprotein levels, patients with tumor size $\leq 5.0 \mathrm{~cm}$ and patients in Barcelona Clinic Liver Cancer stage A, high NOX1 expression had unfavorable effects on RFS, whereas low NOX4 expression had unfavorable effects on both RFS and OS. Conclusions: These findings demonstrated that NOX1 and NOX4 protein expression had opposite prognostic effects for HCC patients. Moreover, both proteins had prognostic value in $\mathrm{HCC}$ patients with normal $\alpha$-fetoprotein levels or with early-stage HCC. (Gut Liver 2016;10:826-835)

Key Words: NOX1; NOX4; Carcinoma, hepatocellular; Prognosis

\section{INTRODUCTION}

Hepatocellular carcinoma (HCC) has a poor prognosis because it is associated with a high incidence of tumor recurrence and metastasis even after hepatectomy. ${ }^{1,2}$ It is important to predict the outcome of HCC patients in order to provide timely intervention after hepatectomy. ${ }^{3}$

Nicotinamide adenine dinucleotide phosphate oxidase (NOX) is a multimeric transmembrane enzyme complex that generates superoxide and hydrogen peroxide from molecular oxygen in response to a wide range of stimuli. ${ }^{4}$ The mammalian NOX family comprises seven isoforms: NOX1, NOX2, NOX3, NOX4, NOX5, dual oxidase 1 , and dual oxidase $2 .{ }^{4,5}$ NOX-mediated reactive oxygen species (ROS) contribute to various liver diseases, including chronic hepatitis, ${ }^{6}$ alcohol-induced liver disease, ${ }^{7}$ cholestatic liver injury, ${ }^{8}$ hepatic fibrosis, ${ }^{9-11}$ and HCC. ${ }^{12}$ NOXdependent ROS production differs with both tumor origin and NOX isoform. ${ }^{13}$ The NOX family promotes angiogenesis and is associated with the metastatic potential of many solid tumors. ${ }^{14}$ NOX1 messenger RNA (mRNA) was up regulated in human colon cancer and gastric adenocarcinoma. ${ }^{15}$ NOX4 overexpression has been found in human gastric adenocarcinoma, ovarian cancer, malignant melanoma, and glioma. ${ }^{15,16} \mathrm{~A}$ recent study found that ROS levels, superoxide production, and NOX activity were about twofold more elevated in invasive HCC SKHep1 cells over those of HepG2 cells. ${ }^{17}$ Lu et al. ${ }^{12}$ reported that NOX4 mRNA expression was higher in HCC than in adjacent nontumor tissue and suggested that NOX4 was not a prognostic factor of HCC after hepatectomy. However, uncertainties remain about whether NOX1 and NOX4 proteins are overexpressed in HCC and the prognostic significance of their expression in HCC.

In 227 HCC patients with long-term follow-up, NOX1 and NOX4 protein expression was investigated by immunohistochemistry to determine whether these proteins can serve as prognostic predictors.

Correspondence to: Cheol-Keun Park

Department of Pathology, Samsung Medical Center, Sungkyunkwan University School of Medicine, 81 Irwon-ro, Gangnam-gu, Seoul 06351, Korea

Tel: +82-2-3410-2766, Fax: +82-2-3410-0025, E-mail: ckpark@skku.edu

Received on October 23, 2015. Revised on December 2, 2015. Accepted on December 31, 2015. Published online June 13, 2016

pISSN 1976-2283 eISSN 2005-1212 http://dx.doi.org/10.5009/gnl15543

@ This is an Open Access article distributed under the terms of the Creative Commons Attribution Non-Commercial License (http://creativecommons.org/licenses/by-nc/4.0) which permits unrestricted non-commercial use, distribution, and reproduction in any medium, provided the original work is properly cited. 


\section{MATERIALS AND METHODS}

\section{Patients}

Primary HCC tissues were obtained from 227 patients who underwent hepatectomy from July 2000 to May 2006 at Samsung Medical Center, Seoul, Korea. All patients were clinically diagnosed with HCC according to the guidelines of the American Association for the Study of Liver Diseases. ${ }^{18}$ Patients were considered for liver resection if they had a single mass in one lobe of liver without evidence of extrahepatic or lymph node metastases. Patients with gross vascular invasion on imaging were only considered for hepatectomy if the main portal vein and the portal branches to the remaining liver were patent. Patients were not considered for hepatectomy if they had a serum total bilirubin level $\geq 1.5 \mathrm{mg} / \mathrm{dL}$, indocyanine green scores $\geq 20 \%$, or ascites. All tumor tissues were histologically confirmed. None of the patients had received preoperative or postoperative adjuvant therapy or radiation therapy. The Institutional Review Board of Samsung Medical Center approved this study. Tumor stages were classified according to both the American Joint Committee on Cancer (AJCC) staging system ${ }^{19}$ and Barcelona Clinic Liver Cancer (BCLC) staging classification. ${ }^{20}$ Intrahepatic metastasis and multicentric occurrence were defined according to the previously reported criteria. ${ }^{21}$ Tumor tissue array blocks were constructed as previously described..$^{22}$ Two 2-mm cores from paraffin blocks of each specimen were taken. As controls, two cores of normal liver tissue from 12 patients with metastatic colon carcinoma of the liver were included in each array block.

All patients were followed by monitoring serum $\alpha$-fetoprotein levels and three phase dynamic computed tomography scans or magnetic resonance imaging every 3 months after surgery. Recurrence-free survival (RFS) was defined from the date of resection until the date of tumor recurrence, metastasis, or last follow-up. Overall survival (OS) was defined from the date of resection until the date of death or last follow-up.

\section{Immunohistochemical analysis}

Immunohistochemical staining was performed as previously described. ${ }^{22}$ Epitope retrieval was performed with $0.01 \mathrm{~mol} /$ L citrate buffer at $\mathrm{pH} 6.0$ for 30 minutes in a pressure cooker. The sections were incubated with rabbit polyclonal antibodies to NOX1 (NBP1-83346, 1:400; Novus Biologicals, Littleton, CO, USA) and NOX4 (ab60940, 1:200; Abcam Corp., Cambridge, MA, USA) for 60 minutes at room temperature. To validate the concordance between tissue microarrays and whole tumor sections, NOX1 and NOX4 expression was also detected for 40 corresponding whole tumor sections randomly chosen from the 227 cases. All reactions were performed using appropriate negative and positive controls. No immunoreactivity was observed in tissue sections used as negative controls in which the primary antibodies were replaced by pre-immune rabbit serum. Positive controls (human normal liver and human normal kid- ney) showed cytoplasmic NOX1 expression in hepatocytes and cytoplasmic NOX4 expression in epithelial cells of convoluted tubules, respectively.

Two independent pathologists (C.K.P. and S.Y.H.) who did not know patient characteristics assessed immunohistochemical staining, and any discrepancies were resolved by consensus. Nearly homogeneous cytoplasmic immunostaining with moderate staining intensity was observed. To determine NOX1 or NOX4 expression, the percentage of stained tumor cells was scored from $0 \%$ to $100 \%$. NOX 1 or NOX4 immunoreactivity was graded as low (0\% to 50\% stained tumor cells regardless of staining intensity) or high expression ( $>50 \%$ stained tumor cells). Duplicate tissue cores for each tumor showed high levels of homogeneity for the proportion of stained cells. In cases of differences between duplicate tissue cores, the higher score was taken.

\section{Statistical analysis}

All statistical analyses were performed using SPSS software version 18 (SPSS Inc., Chicago, IL, USA). The correlation between NOX1 or NOX4 expression and clinicopathologic features was examined by chi-square test or Fisher exact test. Survival curves were constructed using the Kaplan-Meier method, and differences in survival were evaluated using a log-rank test. Univariate and multivariable analyses of survival were performed using the Cox proportional hazards regression model. We confirmed that there was no multicollinearity among variables by using variance inflation factor, and checked the pro-

Table 1. Baseline Patient Characteristics

\begin{tabular}{lc}
\hline Characteristic & No. (\%) \\
\hline Subject no. & 227 \\
Age, yr & $53.0(17-76)$ \\
Male sex & $184(81.1)$ \\
Cirrhosis & $117(51.5)$ \\
AFP level, ng/mL* & $92.0(1-1,667,054)$ \\
Albumin level, g/dL & $4.0(2.8-5.0)$ \\
Etiology & $177(78.0)$ \\
Hepatitis B virus & $21(9.2)$ \\
Hepatitis C virus & $29(12.8)$ \\
Nonviral & $4.0(1-21)$ \\
Tumor size, cm & \\
AJCC T-stage & $96(32.7)$ \\
1 & $4(1.8)$ \\
2 &
\end{tabular}

Data are presented as number (\%) or median (range). AFP, $\alpha$-fetoprotein; AJCC, American Joint Committee on Cancer. *Partial data were not available $(\mathrm{n}=218)$. 
Table 2. Clinical and Tumor Characteristics of the Patients according to NOX1 and NOX4 Protein Expression

\begin{tabular}{|c|c|c|c|c|c|c|}
\hline Characteristic & No. & High NOX1 expression & p-value & No. & Low NOX4 expression & p-value \\
\hline \multicolumn{7}{|l|}{ Age, yr } \\
\hline$\leq 55$ & 135 & $117(86.7)$ & \multirow[t]{2}{*}{0.95} & 135 & $77(57.0)$ & \multirow[t]{2}{*}{0.01} \\
\hline$>55$ & 92 & $80(87.0)$ & & 92 & $35(38.8)$ & \\
\hline \multicolumn{7}{|l|}{ Gender } \\
\hline Female & 43 & $38(88.4)$ & \multirow[t]{2}{*}{0.73} & 43 & $21(48.8)$ & \multirow[t]{2}{*}{0.94} \\
\hline Male & 184 & $159(86.4)$ & & 184 & $91(49.5)$ & \\
\hline \multicolumn{7}{|l|}{ Tumor size, $\mathrm{cm}$} \\
\hline$\leq 5.0$ & 141 & $121(85.8)$ & \multirow{2}{*}{0.58} & 141 & 69 (48.9) & \multirow{2}{*}{0.88} \\
\hline$>5.0$ & 86 & $76(88.4)$ & & 86 & $43(50.0)$ & \\
\hline \multicolumn{7}{|l|}{ Edmondson grade } \\
\hline I & 21 & $17(81.0)$ & \multirow[t]{3}{*}{0.26} & 21 & $6(28.6)$ & \multirow[t]{3}{*}{0.01} \\
\hline II & 156 & $139(89.1)$ & & 156 & $73(46.8)$ & \\
\hline III & 50 & $41(82.0)$ & & 50 & $33(66.0)$ & \\
\hline \multicolumn{7}{|l|}{ Microvascular invasion } \\
\hline$(-)$ & 100 & 85 (85.0) & \multirow[t]{2}{*}{0.48} & 100 & 39 (39.0) & \multirow[t]{2}{*}{0.01} \\
\hline$(+)$ & 127 & $112(88.2)$ & & 127 & 73 (57.5) & \\
\hline Major portal vein invasio & & & & & & \\
\hline$(-)$ & 217 & $188(86.6)$ & 1 & 217 & $103(47.5)$ & 0.01 \\
\hline$(+)$ & 10 & $9(90.0)$ & & 10 & $9(90.0)$ & \\
\hline Intrahepatic metastasis & & & & & & \\
\hline$(-)$ & 171 & $144(84.2)$ & 0.04 & 171 & 75 (43.9) & $<0.01$ \\
\hline$(+)$ & 56 & 53 (94.6) & & 56 & $37(66.1)$ & \\
\hline Multicentric occurrence & & & & & & \\
\hline$(-)$ & 217 & 190 (87.6) & 0.13 & 217 & $105(48.4)$ & 0.21 \\
\hline$(+)$ & 10 & 7 (70.0) & & 10 & 7 (70.0) & \\
\hline AJCC T-stage & & & & & & \\
\hline 1 & 97 & $82(84.5)$ & 0.63 & 97 & $37(38.1)$ & 0.01 \\
\hline 2 & 86 & 74 (86.0) & & 86 & 47 (54.7) & \\
\hline 3 & 40 & 37 (92.5) & & 40 & $26(65.0)$ & \\
\hline 4 & 4 & $4(100.0)$ & & 4 & $2(50.0)$ & \\
\hline BCLC stage & & & & & & \\
\hline A & 122 & $104(85.2)$ & 0.84 & 122 & $57(46.7)$ & 0.08 \\
\hline B & 94 & 83 (88.3) & & 94 & 46 (48.9) & \\
\hline $\mathrm{C}$ & 11 & 10 (90.9) & & 11 & 9 (81.8) & \\
\hline Albumin level, g/dL & & & & & & \\
\hline$>3.5$ & 200 & $174(87.0)$ & 0.76 & 200 & $98(49.0)$ & 0.78 \\
\hline$\leq 3.5$ & 27 & 23 (85.2) & & 27 & 14 (51.9) & \\
\hline AFP level, ng/mL* & & & & & & \\
\hline$\leq 20$ & 84 & 72 (85.7) & 0.74 & 84 & $56(66.7)$ & $<0.01$ \\
\hline$>20$ & 134 & 117 (87.3) & & 134 & $55(41.0)$ & \\
\hline Etiology & & & & & & \\
\hline Nonviral & 29 & $28(96.6)$ & 0.22 & 29 & $7(24.1)$ & $<0.01$ \\
\hline HBV & 177 & $150(84.7)$ & & 177 & $98(55.4)$ & \\
\hline $\mathrm{HCV}$ & 21 & 19 (90.5) & & 21 & 7 (33.3) & \\
\hline Liver cirrhosis & & & & & & \\
\hline$(-)$ & 110 & 97 (88.2) & 0.55 & 110 & 60 (54.5) & 0.26 \\
\hline$(+)$ & 117 & $100(85.5)$ & & 117 & 55 (47.0) & \\
\hline Recurrence site & & & & & & \\
\hline Intrahepatic & 134 & $126(94.0)$ & 0.13 & 134 & $56(41.8)$ & 0.15 \\
\hline Extrahepatic & 19 & 18 (94.7) & & 19 & $10(52.6)$ & \\
\hline Intra- \& extrahepatic & 15 & $12(80.0)$ & & 15 & $3(20.0)$ & \\
\hline Early recurrence ( $\leq 2 \mathrm{yr}$ ) & & & & & & \\
\hline$(-)$ & 98 & 76 (77.6) & $<0.01$ & 98 & $28(28.6)$ & $<0.01$ \\
\hline$(+)$ & 129 & $121(93.8)$ & & 129 & $84(65.1)$ & \\
\hline Late recurrence (>2 yr) & & & & & & \\
\hline$(-)^{\dagger}$ & 59 & $41(69.5)$ & 0.03 & 59 & $13(22.0)$ & 0.08 \\
\hline$(+)$ & 39 & $35(89.7)$ & & 39 & 15 (38.5) & \\
\hline Death & & & & & & \\
\hline$(-)$ & 118 & $95(80.5)$ & $<0.01$ & 118 & $44(40.4)$ & $<0.01$ \\
\hline$(+)$ & 109 & $102(93.6)$ & & 109 & $71(60.2)$ & \\
\hline
\end{tabular}

Data are presented as number $(\%)$.

NOX, nicotinamide adenine dinucleotide phosphate oxidase; AJCC, American Joint Committee on Cancer; BCLC, Barcelona Clinic Liver Cancer; AFP, $\alpha$-fetoprotein; HBV, hepatitis B virus; HCV, hepatitis $\mathrm{C}$ virus.

*Partial data were not available $(\mathrm{n}=218) ;{ }^{\dagger}$ No early or late recurrence. 
portional hazard assumption graphically and confirmed that all variables in Cox proportional hazard model were constants that do not depend on time. The p-values $<0.05$ were defined as statistically significant.

\section{RESULTS}

\section{Clinicopathologic characteristics of patients}

Table 1 lists the baseline characteristics of the patients. The median age was 53.0 years and 184 (81.1\%) were males. Median tumor size was $4.0 \mathrm{~cm}$, and 141 of the 227 tumors (62.1\%) were $\leq 5 \mathrm{~cm}$ in size. The median follow-up period was 120.3 months (range, 14.0 to 151.4 months) for survivors. Tumor recurrence was detected in 168 patients (74.0\%) (Table 2). Ninety-two patients (40.5\%) died of HCC. Of the 109 deaths, 17 were due to non-HCC causes. Eleven of these 17 deaths were due to hepatic failure, four were due to nonhepatic causes (one due to cerebral infarction, one due to myocarditis, one due to aspiration pneumonia, one due to recurred pancreas cancer), and two were due to unknown causes.

\section{NOX1 and NOX4 protein expression in HCC}

Both NOX1 and NOX4 expression were observed in the cytoplasm in $40 \%$ to $60 \%$ of normal hepatocytes with weak staining intensity. In HCC, immunoreactivity for both NOX1 and NOX4 were observed in the cytoplasm in $1 \%$ to $95 \%$ of tumor cells with moderate staining intensity. High NOX1 immunoreactivity was observed in 197 of the 227 HCC cases (86.8\%) (Fig. 1A). High NOX1 expression was significantly correlated with intrahepatic metastasis $(p=0.04)$, early recurrence $(p<0.01)$, late recurrence $(\mathrm{p}=0.03)$, and death $(\mathrm{p}<0.01)$. Low NOX4 immunore- activity was observed in 112 (49.3\%) of the 227 HCC cases (Fig. 1B). Low NOX4 expression was significantly correlated with younger age $(p=0.01)$, higher Edmondson grade $(p=0.01)$, microvascular invasion $(p=0.01)$, major portal vein invasion $(p=0.01)$, intrahepatic metastasis $(\mathrm{p}<0.01)$, higher AJCC T-stage $(\mathrm{p}=0.01)$, higher $\alpha$-fetoprotein level $(p<0.01)$, viral etiology $(p<0.01)$, early recurrence $(\mathrm{p}<0.01)$, and death $(\mathrm{p}<0.01)$ (Table 2$)$.

\section{Correlation between NOX1 and NOX4 expression and prognosis of HCC patients}

The RFS and OS rates for 227 HCC patients were 37.4\% and $74.7 \%$ at 3 years, $32.4 \%$ and $65.2 \%$ at 5 years, $26.5 \%$ and $56.8 \%$ at 7 years, and $25.8 \%$ and $50.3 \%$ at 9 years, respectively. On univariable analysis, larger tumor size, Edmondson grade III, microvascular invasion, major portal vein invasion, intrahepatic metastasis, and lower albumin level showed unfavorable effects on both RFS and OS. Higher $\alpha$-fetoprotein level and viral etiology showed unfavorable effects on RFS (Tables 3 and 4).

High NOX1 expression showed an unfavorable effect on RFS (Table 3). The 5-year RFS rate of the high NOX1 expression group was significantly lower than that of the low NOX1 expression group (27.6\% vs 63.3\%) $(\mathrm{p}<0.001)$ (Fig. 2A). The mean RFS of the high NOX1 expression group and the low NOX1 expression group were 42.9 and 97.3 months, respectively. Subgroup analysis showed that among patients with $\alpha$-fetoprotein $\leq 20 \mathrm{ng} / \mathrm{mL}(\mathrm{n}=84)$, patients with tumor size $\leq 5.0 \mathrm{~cm}(\mathrm{n}=141)$, and patients at BCLC stage A $(n=122)$, there were significant differences in RFS between high NOX1 expression groups ( $\mathrm{n}=72$, $n=121$, and $n=104$, respectively) and low NOX1 expression groups ( $\mathrm{p}=0.020, \mathrm{p}=0.013$, and $\mathrm{p}=0.029$, respectively) (Fig. 2B-D).

High NOX1 expression showed an unfavorable effect on
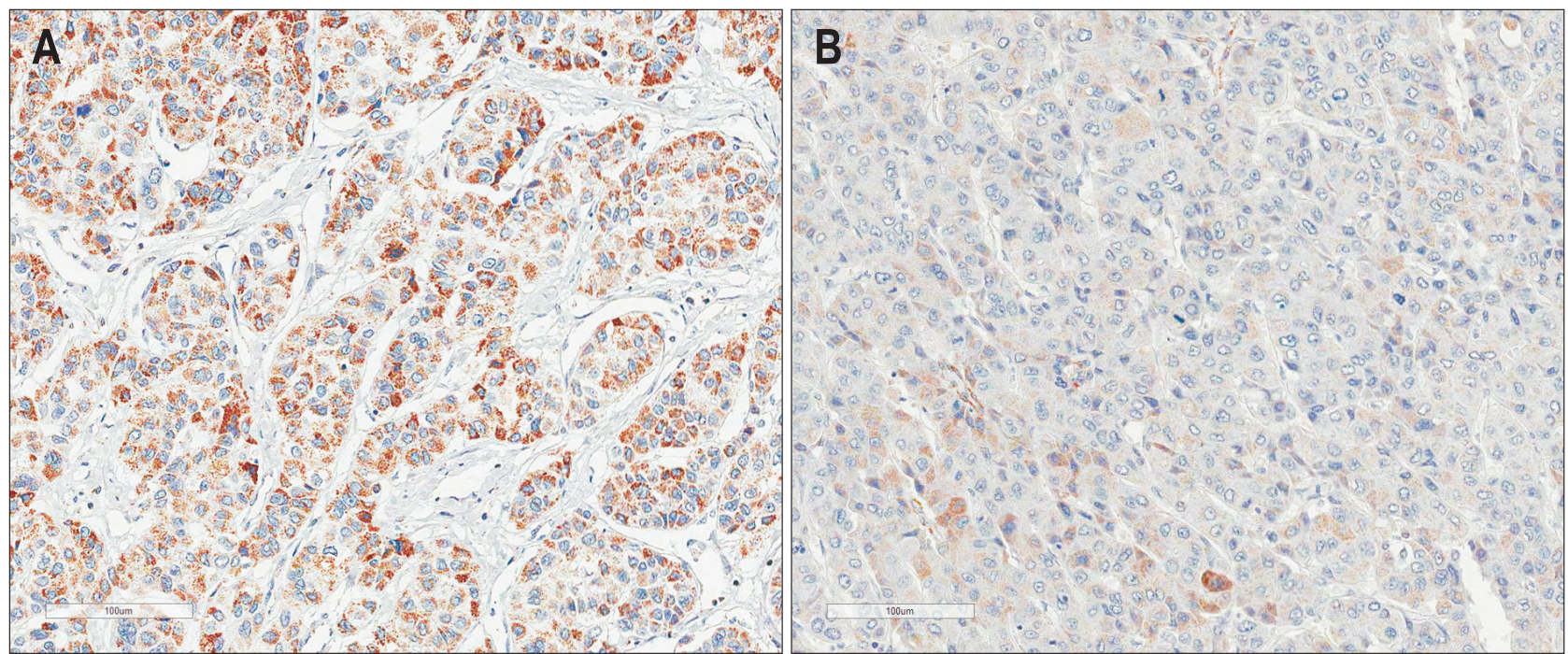

Fig. 1. Immunostaining of NOX1 and NOX4 in hepatocellular carcinoma shows high cytoplasmic immunoreactivity for NOX1 (A) and low cytoplasmic immunoreactivity for NOX4 (B) (horseradish peroxidase stain, $\times 200$ ). NOX, nicotinamide adenine dinucleotide phosphate oxidase. 
Table 3. Univariate and Multivariable Analyses of Recurrence-Free Survival in 227 Hepatocellular Carcinomas

\begin{tabular}{|c|c|c|c|c|}
\hline \multirow{2}{*}{ Variable } & \multicolumn{2}{|c|}{ Univariate analysis } & \multicolumn{2}{|c|}{ Multivariable analysis } \\
\hline & $\mathrm{HR}(95 \% \mathrm{CI})$ & $\mathrm{p}$-value & $\mathrm{HR}(95 \% \mathrm{CI})$ & p-value \\
\hline Age $>55$ yr & $0.96(0.70-1.30)$ & 0.78 & - & - \\
\hline Male sex & $1.00(0.69-1.47)$ & 0.98 & - & - \\
\hline Tumor size $>5 \mathrm{~cm}$ & $1.63(1.19-2.22)$ & $<0.01$ & $1.49(1.00-2.23)$ & 0.05 \\
\hline Edmondson grade III* & $1.74(1.23-2.47)$ & $<0.01$ & $1.10(0.67-1.53)$ & 0.95 \\
\hline Microvascular invasion & $2.36(1.72-3.24)$ & $<0.01$ & $1.76(1.17-2.65)$ & 0.01 \\
\hline Major portal vein invasion & $2.97(1.51-5.85)$ & $<0.01$ & $0.85(0.39-1.85)$ & 0.68 \\
\hline Intrahepatic metastasis & $3.89(2.77-5.46)$ & $<0.01$ & $1.83(0.17-2.86)$ & 0.01 \\
\hline Multicentric occurrence & $1.47(0.75-2.89)$ & 0.26 & - & - \\
\hline Albumin level $\leq 3.5 \mathrm{~g} / \mathrm{dL}$ & $1.77(1.15-2.73)$ & 0.01 & $1.58(0.98-2.54)$ & 0.06 \\
\hline AFP level >20 ng/mL ${ }^{\dagger}$ & $1.50(1.08-2.07)$ & 0.02 & $0.98(0.69-1.39)$ & 0.90 \\
\hline Etiology, viral $^{\ddagger}$ & $2.24(1.29-3.87)$ & $<0.01$ & $1.69(0.93-3.10)$ & 0.09 \\
\hline Liver cirrhosis & $1.32(0.97-1.78)$ & 0.08 & $1.40(0.98-2.01)$ & 0.07 \\
\hline High NOX1 expression & $3.01(1.67-5.44)$ & $<0.01$ & $5.15(2.68-9.90)$ & $<0.01$ \\
\hline Low NOX4 expression & $2.61(1.90-3.57)$ & $<0.01$ & $2.87(2.00-4.11)$ & $<0.01$ \\
\hline
\end{tabular}

The complete data analysis was performed.

$\mathrm{HR}$, hazard ratio; CI, confidence interval; AFP, $\alpha$-fetoprotein; NOX, nicotinamide adenine dinucleotide phosphate oxidase.

${ }^{*}$ Edmondson grades I and II served as references; ${ }^{\dagger}$ Partial data were not available $(n=218)$; ${ }^{\ddagger}$ Nonviral causes served as a reference.

Table 4. Univariate and Multivariable Analyses of Overall Survival in 227 Hepatocellular Carcinomas

\begin{tabular}{|c|c|c|c|c|}
\hline \multirow{2}{*}{ Variable } & \multicolumn{2}{|c|}{ Univariate analysis } & \multicolumn{2}{|c|}{ Multivariable analysis } \\
\hline & $\operatorname{HR}(95 \% \mathrm{CI})$ & p-value & HR (95\% CI) & p-value \\
\hline Age $>55$ yr & $1.12(0.76-1.63)$ & 0.57 & - & - \\
\hline Male sex & $1.30(0.79-2.13)$ & 0.30 & - & - \\
\hline Tumor size $>5 \mathrm{~cm}$ & $2.45(1.68-3.57)$ & $<0.01$ & $1.72(1.05-2.83)$ & 0.03 \\
\hline Edmondson grade III* & $1.78(1.17-2.72)$ & 0.01 & $0.97(0.60-1.57)$ & 0.90 \\
\hline Microvascular invasion & $2.88(1.90-4.36)$ & $<0.01$ & $1.44(0.82-2.53)$ & 0.20 \\
\hline Major portal vein invasion & $5.25(2.62-10.49)$ & $<0.01$ & $1.59(0.72-3.52)$ & 0.26 \\
\hline Intrahepatic metastasis & $5.76(3.90-8.52)$ & $<0.01$ & $3.14(1.84-5.35)$ & $<0.01$ \\
\hline Multicentric occurrence & $0.82(0.30-2.21)$ & 0.69 & - & - \\
\hline Albumin level $\leq 3.5 \mathrm{~g} / \mathrm{dL}$ & $2.46(1.51-4.01)$ & $<0.01$ & $2.33(1.39-3.93)$ & $<0.01$ \\
\hline AFP level >20 ng/mL ${ }^{\dagger}$ & $1.47(0.98-2.20)$ & 0.06 & $0.83(0.53-1.30)$ & 0.42 \\
\hline Etiology, viral $^{\ddagger}$ & $1.44(0.79-2.63)$ & 0.23 & $1.07(0.54-2.11)$ & 0.85 \\
\hline Liver cirrhosis & $1.13(0.77-1.64)$ & 0.54 & $1.49(0.94-2.36)$ & 0.09 \\
\hline High NOX1 expression & $2.54(1.18-5.46)$ & 0.02 & $3.18(1.35-7.49)$ & 0.01 \\
\hline Low NOX4 expression & $2.05(1.39-3.00)$ & $<0.01$ & $1.77(1.16-2.72)$ & 0.01 \\
\hline
\end{tabular}

The complete data analysis was performed.

HR, hazard ratio; CI, confidence interval; AFP, $\alpha$-fetoprotein; NOX, nicotinamide adenine dinucleotide phosphate oxidase.

${ }^{*}$ Edmondson grades I and II served as references; ${ }^{\dagger}$ Partial data were not available $(n=218)$; ${ }^{\ddagger}$ Nonviral causes served as a reference.

OS (Table 4). The 5-year OS rate of the high NOX1 expression group was significantly lower than that of the low NOX1 expression group (63.5\% vs 76.7\%) ( $\mathrm{p}=0.014)$ (Fig. 3A). The mean OS of the high NOX1 expression group and the low NOX1 expression group were 92.9 and 120.0 months, respectively. Subgroup analysis showed that among patients with $\alpha$-fetoprotein $\leq 20 \mathrm{ng} / \mathrm{mL}(\mathrm{n}=84)$, patients with tumor size $\leq 5.0 \mathrm{~cm}(\mathrm{n}=141)$, and patients at BCLC stage $A(n=122)$, there were no significant differences in OS between high NOX1 expression groups and low NOX1 expression groups $(\mathrm{p}=0.128, \mathrm{p}=0.131$, and $\mathrm{p}=0.167$, respectively) (Fig. 3B-D). However, subgroup analyses including poor prognostic counterpart factors such as $\alpha$-fetoprotein $>20$ 
A

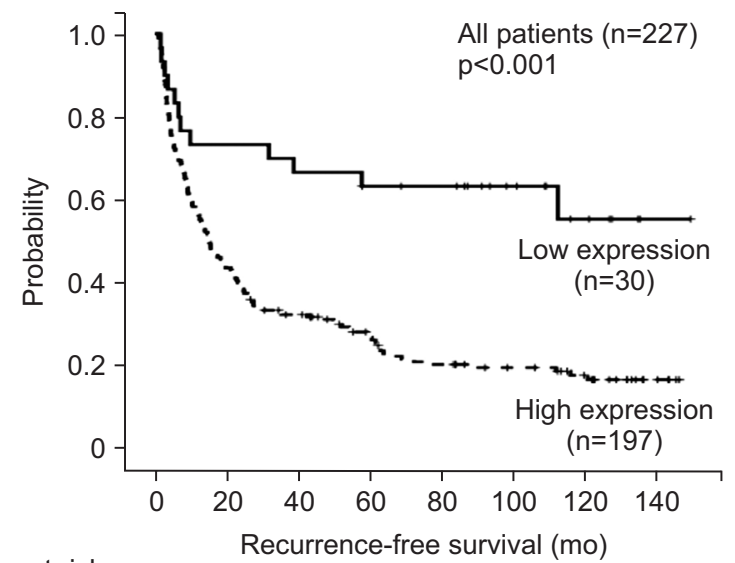

C

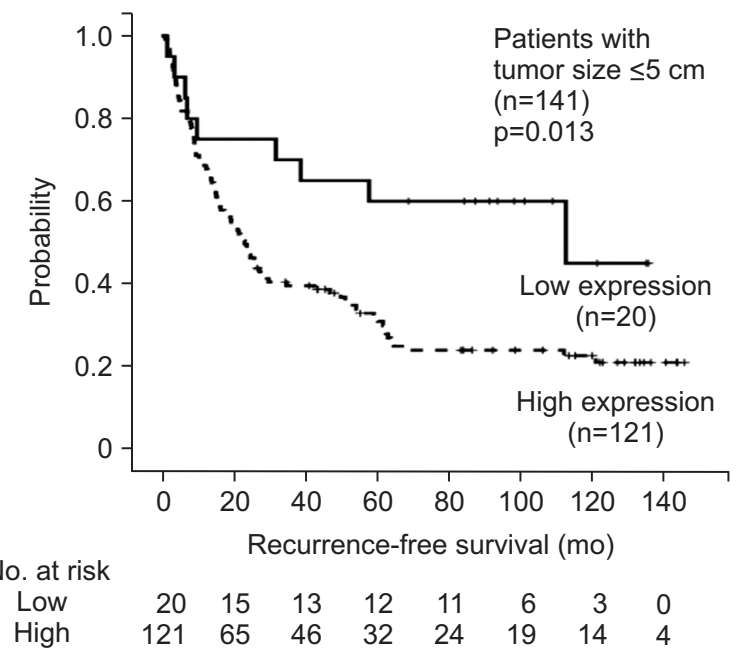

B

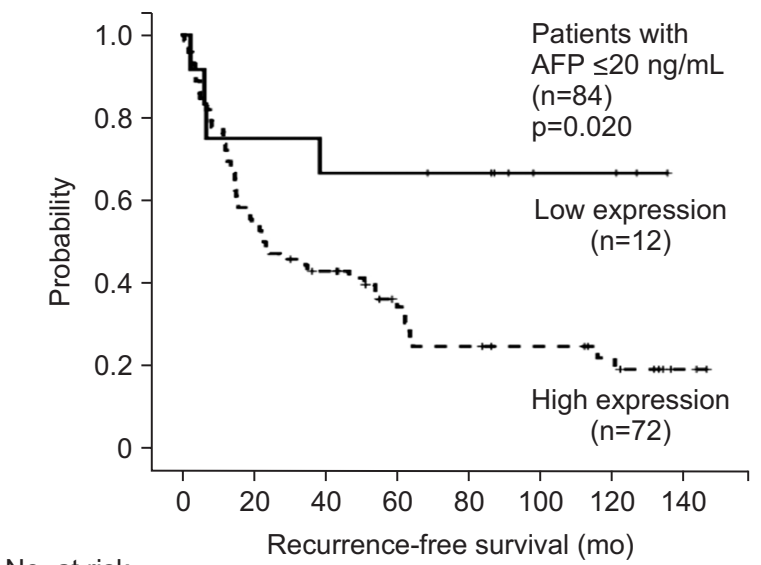

$\begin{array}{lrrrrrrrr}\text { Low } & 12 & 9 & 8 & 8 & 7 & 3 & 3 & 0 \\ \text { High } & 72 & 39 & 29 & 19 & 13 & 11 & 8 & 2\end{array}$

D

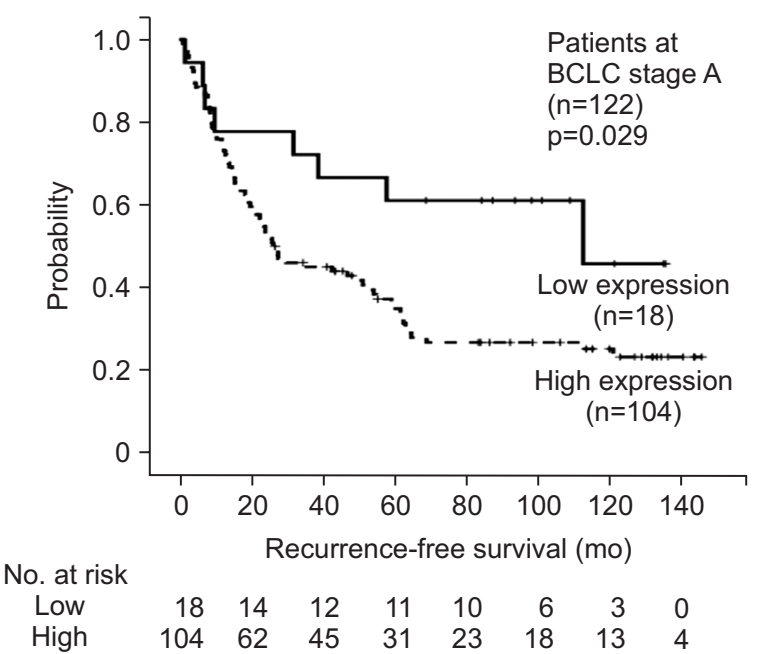

Fig. 2. Kaplan-Meier survival curves showing recurrence-free survival among all patients (A), patients with $\alpha$-fetoprotein (AFP) $\leq 20 \mathrm{ng} / \mathrm{mL}$ (B), patients with tumor size $\leq 5.0 \mathrm{~cm}$ (C), and patients at Barcelona Clinic Liver Cancer (BCLC) stage A (D) according to NOX1 expression. NOX, nicotinamide adenine dinucleotide phosphate oxidase.

$\mathrm{ng} / \mathrm{mL}$, tumor size $>5.0 \mathrm{~cm}$, and BCLC stage B or C showed no significant differences in RFS or OS.

Low NOX4 expression showed an unfavorable effect on RFS (Table 3). The 5-year RFS rate of the low NOX4 expression group was significantly lower than that of the high NOX4 expression group (13.8\% vs 50.5\%) $(\mathrm{p}<0.001)$ (Fig. 4A). The mean RFS of the low NOX4 expression group and the high NOX4 expression group were 26.3 and 72.6 months, respectively. Subgroup analysis showed that among patients with $\alpha$-fetoprotein $\leq 20 \mathrm{ng} / \mathrm{mL}$ ( $\mathrm{n}=84)$, patients with tumor size $\leq 5.0 \mathrm{~cm} \quad(\mathrm{n}=141)$, and patients at BCLC stage A $(n=122)$, there were significant differences in RFS between low NOX4 expression groups ( $n=28$, $n=69$, and $n=57$, respectively) and high NOX4 expression groups ( $\mathrm{p}<0.001, \mathrm{p}<0.001$, and $\mathrm{p}<0.001$, respectively) (Fig. 4BD). A Low NOX4 expression showed an unfavorable effect on OS (Table 4). The 5-year OS rate of the low NOX4 expression group was significantly lower than that of the high NOX4 expression group (51.8\% vs 78.1\%) (p<0.001) (Fig. 5A). The mean OS of the low NOX4 expression group and the high NOX4 expression group were 80.7 and 110.7 months, respectively. Subgroup analysis showed that among patients with $\alpha$-fetoprotein $\leq 20 \mathrm{ng} / \mathrm{mL}(\mathrm{n}=84)$ and patients with tumor size $\leq 5.0 \mathrm{~cm}(\mathrm{n}=141)$, there were significant differences in OS between low NOX4 expression groups and high NOX4 expression groups ( $\mathrm{p}=0.009$ and $\mathrm{p}=0.011$, respectively) (Fig. $5 \mathrm{~B}$ and $\mathrm{C}$ ). Among patients at BCLC stage A ( $n=122)$, the low NOX4 expression group tended to show an unfavorable effect on OS ( $p=0.085$ ) (Fig. 5D). However, subgroup analyses including poor prognostic counterpart factors such as $\alpha$-fetoprotein $>20 \mathrm{ng} / \mathrm{mL}$, tumor size $>5.0 \mathrm{~cm}$, and BCLC stage B or C showed no significant differences in RFS or OS.

Multivariable analysis revealed that intrahepatic metastasis 
A

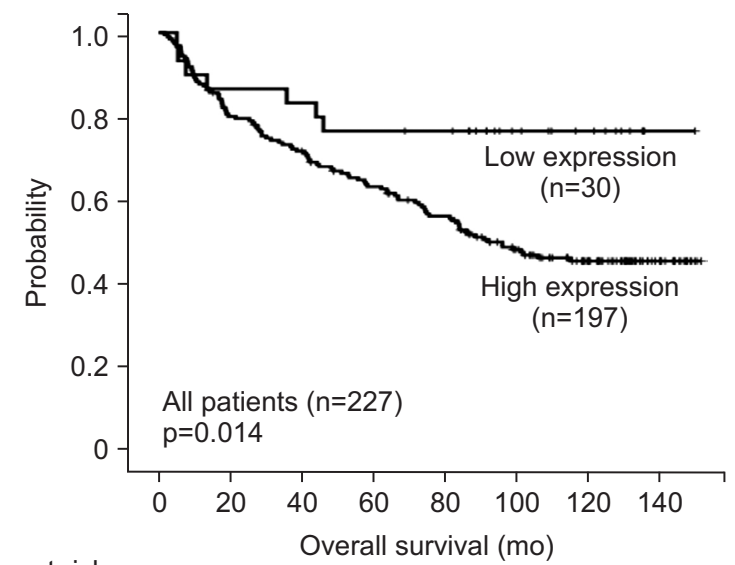

No. at risk

$\begin{array}{lllllllll}\text { Low } & 30 & 26 & 25 & 23 & 22 & 13 & 9 & 1\end{array}$

$\begin{array}{lrrrrrrrr}\text { High } & 197 & 156 & 139 & 120 & 104 & 77 & 52 & 17\end{array}$

C

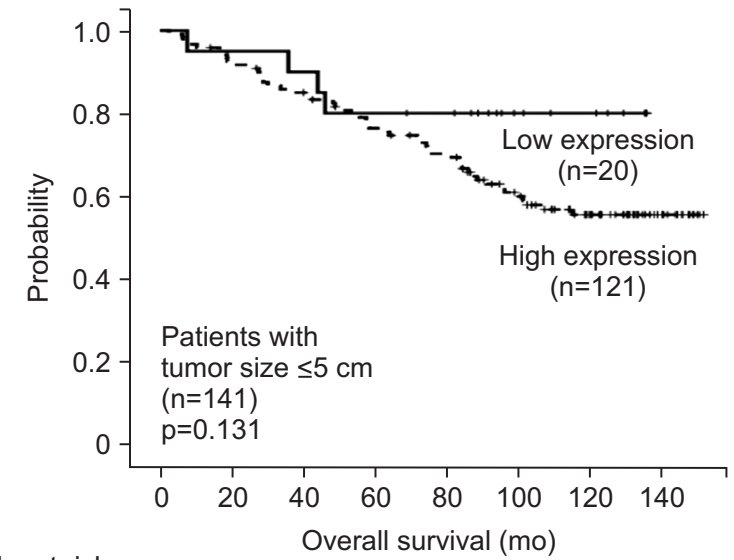

No. at risk

$\begin{array}{lrrrrrrrr}\text { Low } & 20 & 19 & 18 & 16 & 15 & 8 & 6 & 0 \\ \text { High } & 121 & 110 & 101 & 88 & 79 & 59 & 38 & 13\end{array}$

B

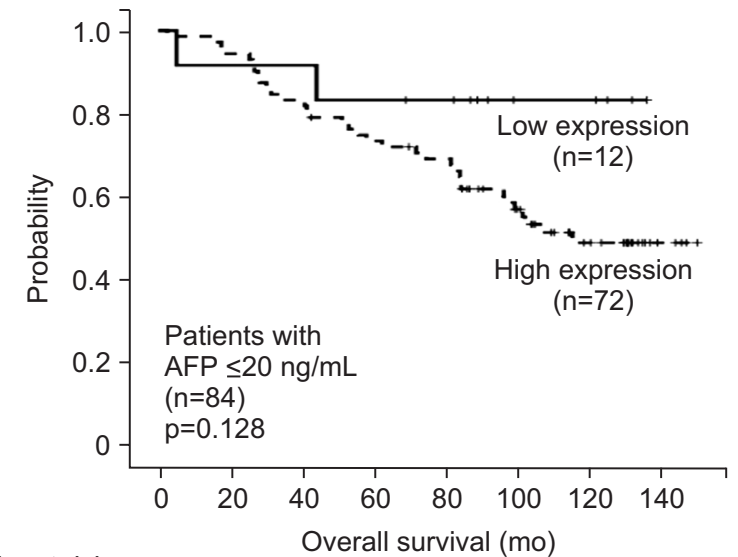

D

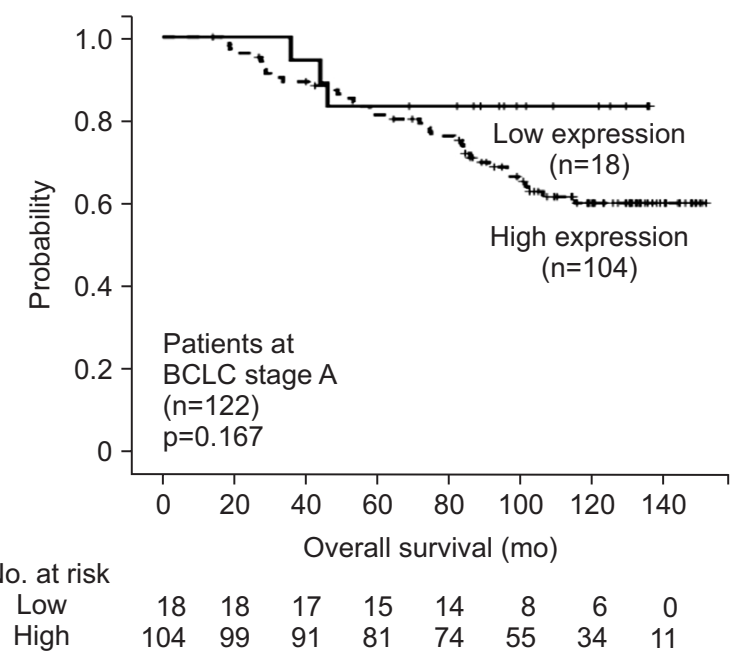

Fig. 3. Kaplan-Meier survival curves showing overall survival among all patients (A), patients with $\alpha$-fetoprotein (AFP) $\leq 20$ ng/mL (B), patients with tumor size $\leq 5.0 \mathrm{~cm}(\mathrm{C})$, and patients at Barcelona Clinic Liver Cancer (BCLC) stage A (D) according to the NOX1 expression. NOX, nicotinamide adenine dinucleotide phosphate oxidase.

was independent predictor of both shorter RFS and shorter OS. Microvascular invasion was independent predictor of shorter RFS. High NOX1 expression and low NOX4 expression were independent predictors of both shorter RFS $(\mathrm{p}<0.01$ and $\mathrm{p}<0.01$, respectively) and shorter $0 S$ ( $p=0.01$ and $p=0.01$, respectively) (Tables 3 and 4).

\section{DISCUSSION}

In mammalian cells, low levels of ROS play an important role in physiological redox signaling. However, low levels of ROS can also induce oxidative stress to cause genomic instability, DNA damage, and possible cancer progression. ${ }^{23}$ Elevated oxidative stress and ROS production by tumor cells and microenvironmental cells contribute to tumor progression and metastasis. ${ }^{24}$ Supporting a role for NOX1 in colon carcinogenesis, activating mutations in the proto-oncogene K-Ras were discovered in concert with NOX1 overexpression in human colon cancers. ${ }^{25}$

This study reports opposite prognostic effects of NOX1 and NOX4 proteins on HCC patients for the first time. High NOX1 protein expression was an independent predictor of both shorter RFS and shorter OS. Low NOX4 protein expression was an independent predictor of both shorter RFS and shorter OS. In mammals, NOX1 produces superoxide and NOX4 produces $\mathrm{H}_{2} \mathrm{O}_{2}{ }^{26}$ Inhibition of NOX1 gene expression with small interfering RNA in human colon cancer cells decreased tumor growth and angiogenesis markers in vivo. ${ }^{27}$ NOX4 knockdown caused increased cell proliferation in both human HCC cells and human and mouse hepatocytes, suggesting that NOX4 plays a negative role in liver cell proliferation, which is consistent with the result of this study. ${ }^{28}$ Lu et al. ${ }^{12}$ reported that NOX4 mRNA expression 
A

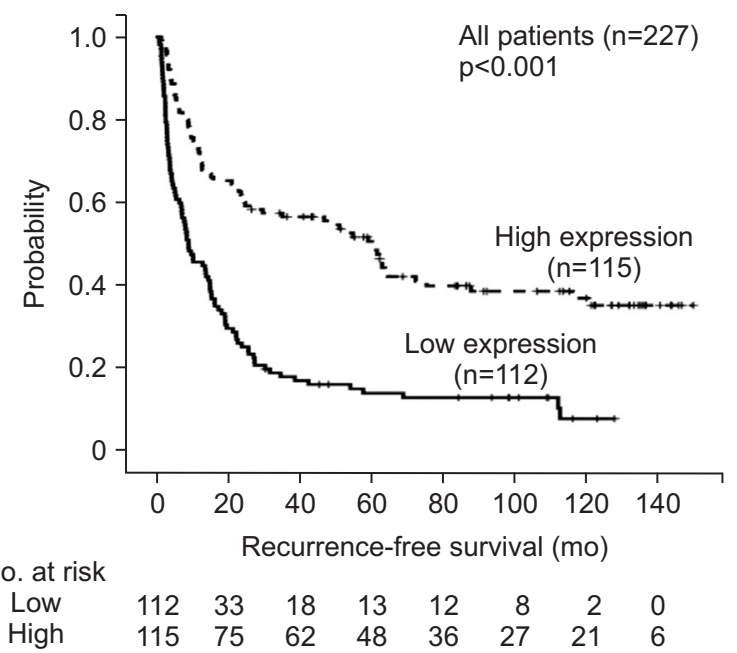

C

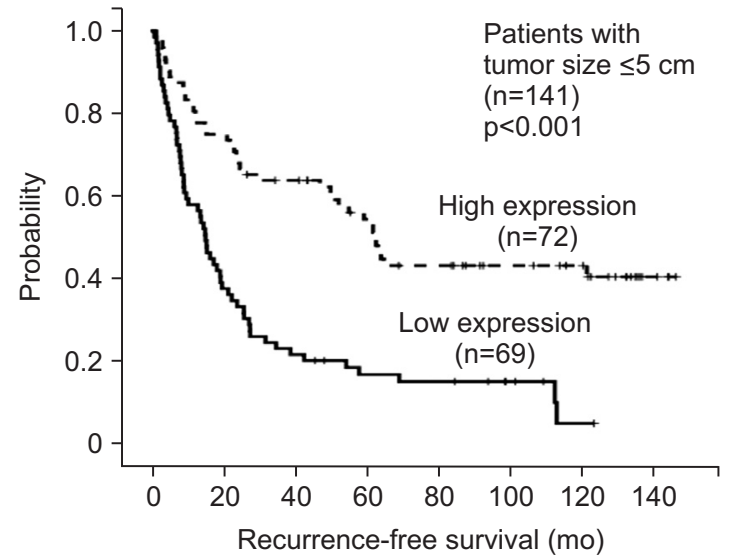

No. at risk

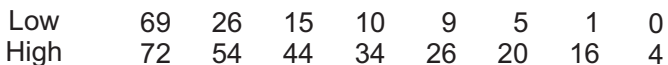

B

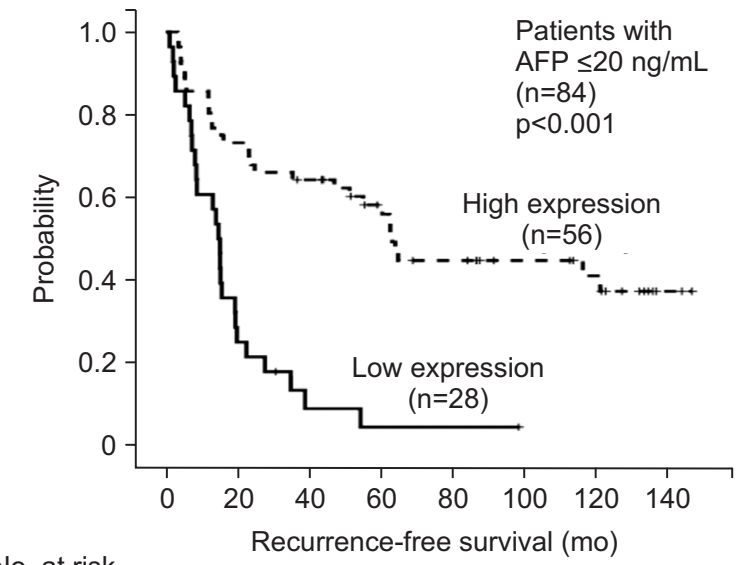

D

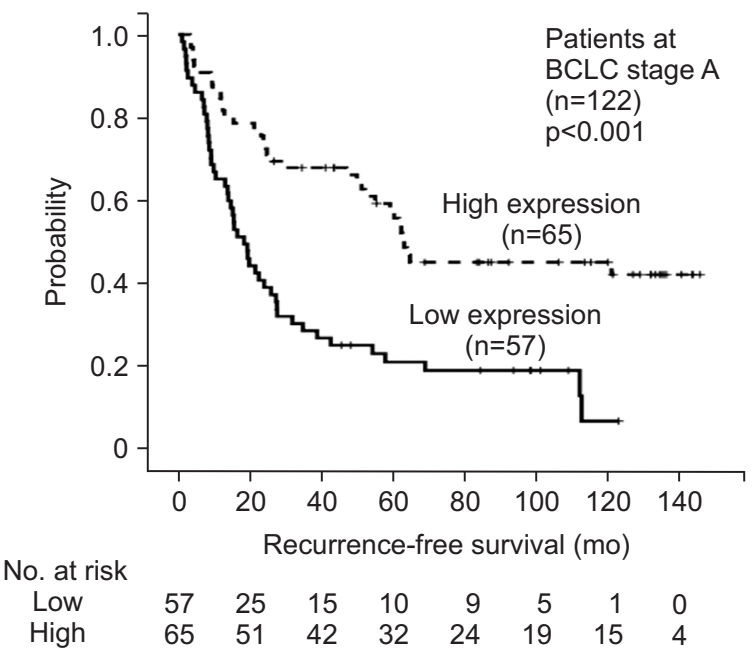

Fig. 4. Kaplan-Meier survival curves showing recurrence-free survival among all patients (A), patients with $\alpha$-fetoprotein (AFP) $\leq 20 \mathrm{ng} / \mathrm{mL}$ (B), patients with tumor size $\leq 5.0 \mathrm{~cm}$ (C), and patients at Barcelona Clinic Liver Cancer (BCLC) stage A (D) according to NOX4 expression. NOX, nicotinamide adenine dinucleotide phosphate oxidase.

was not a prognostic factor for RFS or OS in 107 HCC patients. We investigated the prognostic roles of NOX1 and NOX4 in 227 HCC patients with long-term follow-up.

In this study, tumor recurrence was detected in 57 of 84 patients (67.9\%) with normal serum $\alpha$-fetoprotein levels, in 100 of 141 patients (70.9\%) with tumor size $\leq 5.0 \mathrm{~cm}$, and in 83 of 122 patients (68.0\%) at BCLC stage A. Within these patient populations, high NOX1 expression groups showed unfavorable effects on RFS (Fig. 2) and low NOX4 expression groups showed unfavorable effects on both RFS and OS (Figs 4 and 5). Serum $\alpha$-fetoprotein is an important predictor of HCC recurrence after surgery. Identification of poor prognosis subpopulations for early stage HCC patients is crucial to the optimization of personalized treatment. NOX1 and NOX4 protein expression may help to predict recurrence risk in patients with normal serum $\alpha$-fetoprotein levels and early stage HCC after tumor resection.
Moreover, NOX1 could be a promising therapeutic target for HCC. ML171, a specific NOX1 small-molecule inhibitor, blocked the formation of functional invadopodia in human colon cancer cells and was defined as a potential therapeutic agent for inhibition of cancer cell invasion. ${ }^{29}$ Liu et al. ${ }^{30}$ reported that blockade of NOX1 with ML171 alleviated enhanced non-small cell lung cancer metastasis by TLR4 signaling and suggested that NOX1/ ROS was a promising therapeutic target for non-small cell lung cancer. Due to a high degree of similarity to currently used drugs, the pharmacokinetics and safety data of ML171 likely enable the use of this compound in vivo. ${ }^{31}$

Our results suggest that NOX1 and NOX4 are potential new markers for predicting HCC prognosis after hepatectomy. Patients with high NOX1 expression or low NOX4 expression are considered candidates for adjuvant treatment after surgical resection. However, the molecular mechanism for these opposite 
A

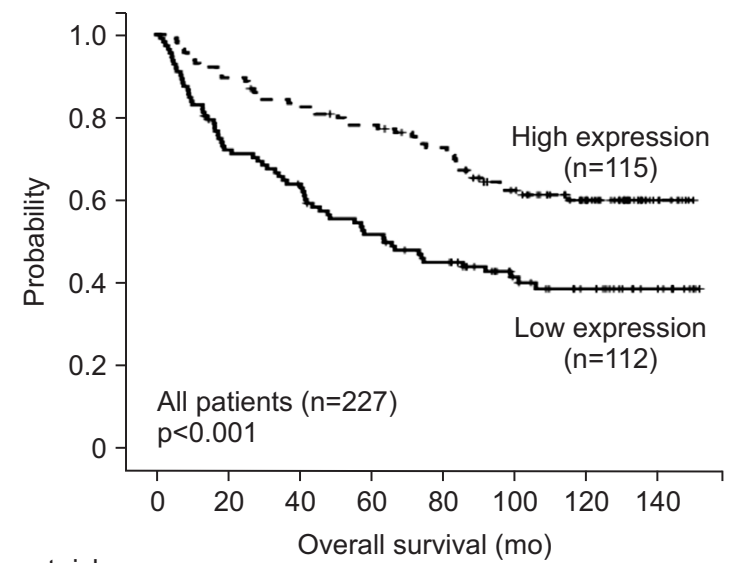

No. at risk

$\begin{array}{lllllllll}\text { Low } & 112 & 79 & 70 & 55 & 46 & 30 & 21 & 9\end{array}$

$\begin{array}{lllllllll}\text { High } & 115 & 103 & 94 & 88 & 80 & 60 & 40 & 9\end{array}$

C

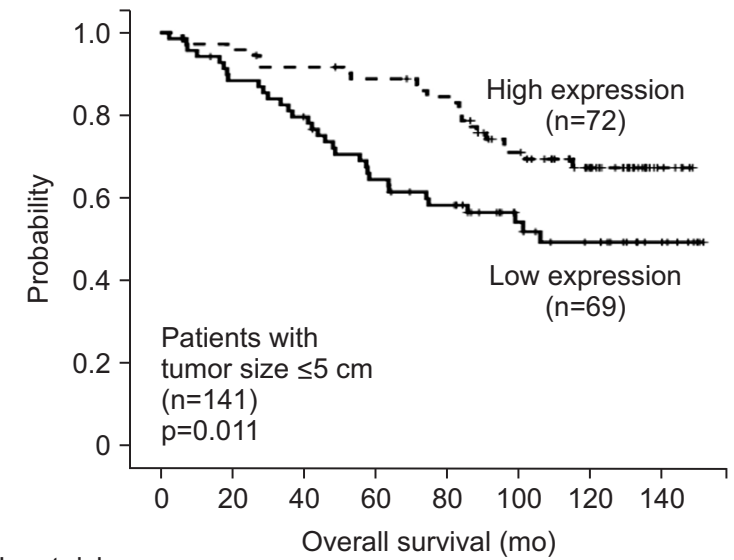

No. at risk

$\begin{array}{lllllllll}\text { Low } & 69 & 60 & 54 & 42 & 36 & 23 & 17 & 7\end{array}$

$\begin{array}{lllllllll}\text { High } & 72 & 69 & 65 & 62 & 58 & 44 & 27 & 6\end{array}$
B

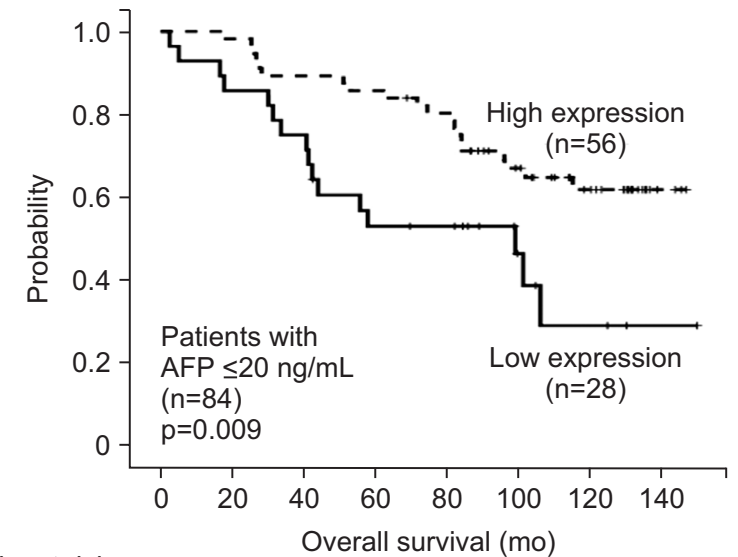

No. at risk

$\begin{array}{rrrrrrrrr}\text { Low } & 28 & 24 & 21 & 14 & 13 & 6 & 3 & 1 \\ \text { High } & 56 & 55 & 50 & 48 & 44 & 31 & 20 & 3\end{array}$

D

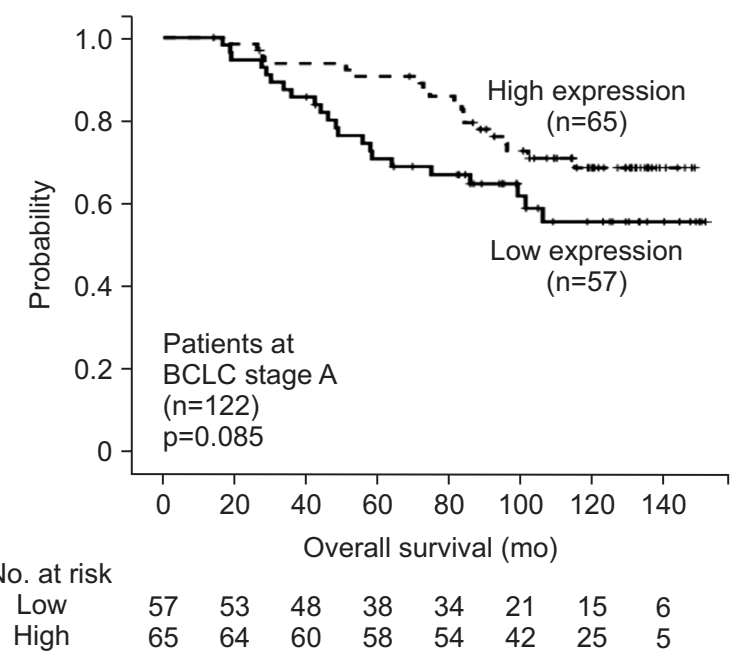

Fig. 5. Kaplan-Meier survival curves showing overall survival among all patients (A), patients with $\alpha$-fetoprotein (AFP) $\leq 20 \mathrm{ng} / \mathrm{mL}$ (B), patients with tumor size $\leq 5.0 \mathrm{~cm}(\mathrm{C})$, and patients at Barcelona Clinic Liver Cancer (BCLC) stage A (D) according to NOX4 expression. NOX, nicotinamide adenine dinucleotide phosphate oxidase.

prognostic effects is unknown.

For the first time, this study demonstrated that NOX1 and NOX4 protein expression had opposite prognostic effects on HCC patients. Moreover, both proteins had prognostic values in HCC patients with early stage HCC or normal serum $\alpha$-fetoprotein levels. These findings also indicate possible new lines of research for developing therapeutic approaches to targeting NOXs. Further study is needed to identify the underlying molecular mechanism of NOX1 and NOX4 in the development and progression of HCC.

\section{CONFLICTS OF INTEREST}

No potential conflict of interest relevant to this article was reported.

\section{ACKNOWLEDGEMENTS}

This study was supported by a Samsung Biomedical Research Institute Grant (\#0TX0002001).

\section{REFERENCES}

1. Poon RT. Prevention of recurrence after resection of hepatocellular carcinoma: a daunting challenge. Hepatology 2011;54:757-759.

2. Llovet JM, Schwartz M, Mazzaferro V. Resection and liver transplantation for hepatocellular carcinoma. Semin Liver Dis 2005;25: 181-200.

3. Qin LX, Tang ZY. Recent progress in predictive biomarkers for metastatic recurrence of human hepatocellular carcinoma: a review of the literature. J Cancer Res Clin Oncol 2004;130:497-513.

4. Bedard K, Krause KH. The NOX family of ROS-generating 
NADPH oxidases: physiology and pathophysiology. Physiol Rev 2007;87:245-313.

5. Lambeth JD. NOX enzymes and the biology of reactive oxygen. Nat Rev Immunol 2004;4:181-189.

6. de Mochel NS, Seronello S, Wang SH, et al. Hepatocyte NAD(P)H oxidases as an endogenous source of reactive oxygen species during hepatitis C virus infection. Hepatology 2010;52:47-59.

7. Kono H, Rusyn I, Yin M, et al. NADPH oxidase-derived free radicals are key oxidants in alcohol-induced liver disease. J Clin Invest 2000;106:867-872.

8. Reinehr R, Becker S, Keitel V, Eberle A, Grether-Beck S, Häussinger D. Bile salt-induced apoptosis involves NADPH oxidase isoform activation. Gastroenterology 2005;129:2009-2031.

9. De Minicis S, Seki E, Paik YH, et al. Role and cellular source of nicotinamide adenine dinucleotide phosphate oxidase in hepatic fibrosis. Hepatology 2010;52:1420-1430.

10. Aoyama T, Paik YH, Watanabe S, et al. Nicotinamide adenine dinucleotide phosphate oxidase in experimental liver fibrosis: GKT137831 as a novel potential therapeutic agent. Hepatology 2012;56:2316-2327.

11. Jiang JX, Chen X, Serizawa N, et al. Liver fibrosis and hepatocyte apoptosis are attenuated by GKT137831, a novel NOX4/NOX1 inhibitor in vivo. Free Radic Biol Med 2012;53:289-296.

12. Lu CL, Qiu JL, Huang PZ, et al. NADPH oxidase DUOX1 and DUOX2 but not NOX4 are independent predictors in hepatocellular carcinoma after hepatectomy. Tumour Biol 2011;32:11731182.

13. Wu Y, Antony S, Juhasz A, et al. Up-regulation and sustained activation of Stat1 are essential for interferon-gamma (IFN-gamma)induced dual oxidase 2 (Duox2) and dual oxidase A2 (DuoxA2) expression in human pancreatic cancer cell lines. J Biol Chem 2011;286:12245-12256.

14. Ushio-Fukai M. VEGF signaling through NADPH oxidase-derived ROS. Antioxid Redox Signal 2007;9:731-739.

15. Juhasz A, Ge Y, Markel S, et al. Expression of NADPH oxidase homologues and accessory genes in human cancer cell lines, tumours and adjacent normal tissues. Free Radic Res 2009;43:523532.

16. Shono T, Yokoyama N, Uesaka T, et al. Enhanced expression of NADPH oxidase Nox4 in human gliomas and its roles in cell proliferation and survival. Int J Cancer 2008;123:787-792.

17. Liu ZM, Tseng HY, Tsai HW, Su FC, Huang HS. Transforming growth factor beta-interacting factor-induced malignant progression of hepatocellular carcinoma cells depends on superoxide pro- duction from Nox4. Free Radic Biol Med 2015;84:54-64.

18. Bruix J, Sherman M; American Association for the Study of Liver Diseases. Management of hepatocellular carcinoma: an update. Hepatology 2011;53:1020-1022.

19. Edge SB, Byrd DR, Compton CC, Fritz AG, Greene FL, Trotti A III. AJCC cancer staging manual. 7th ed. Chicago: Springer, 2010:191195.

20. Llovet JM, Brú C, Bruix J. Prognosis of hepatocellular carcinoma: the BCLC staging classification. Semin Liver Dis 1999;19:329-338.

21. Kumada T, Nakano S, Takeda I, et al. Patterns of recurrence after initial treatment in patients with small hepatocellular carcinoma. Hepatology 1997;25:87-92.

22. Ahn S, Hyeon J, Park CK. Metadherin is a prognostic predictor of hepatocellular carcinoma after curative hepatectomy. Gut Liver 2013;7:206-212.

23. Brigelius-Flohé R, Flohé L. Basic principles and emerging concepts in the redox control of transcription factors. Antioxid Redox Signal 2011;15:2335-2381.

24. Cui X. Reactive oxygen species: the achilles' heel of cancer cells? Antioxid Redox Signal 2012;16:1212-1214.

25. Laurent E, McCoy JW 3rd, Macina RA, et al. Nox1 is overexpressed in human colon cancers and correlates with activating mutations in K-Ras. Int J Cancer 2008;123:100-107.

26. Martyn KD, Frederick LM, von Loehneysen K, Dinauer MC, Knaus UG. Functional analysis of Nox4 reveals unique characteristics compared to other NADPH oxidases. Cell Signal 2006;18:69-82.

27. Juhasz AN, Markel S, Gaur S, et al. Inhibition of NOX1 gene expression with siRNA in human colon cancer cells decrease tumor growth and markers of angiogenesis in vivo. Cancer Res 2005;65(9 Suppl):1436.

28. Crosas-Molist E, Bertran E, Sancho P, et al. The NADPH oxidase NOX4 inhibits hepatocyte proliferation and liver cancer progression. Free Radic Biol Med 2014;69:338-347.

29. Gianni D, Taulet N, Zhang H, et al. A novel and specific NADPH oxidase-1 (Nox1) small-molecule inhibitor blocks the formation of functional invadopodia in human colon cancer cells. ACS Chem Biol 2010;5:981-993.

30. Liu X, Pei C, Yan S, et al. NADPH oxidase 1-dependent ROS is crucial for TLR4 signaling to promote tumor metastasis of nonsmall cell lung cancer. Tumour Biol 2015;36:1493-1502.

31. Altenhöfer S, Radermacher KA, Kleikers PW, Wingler K, Schmidt HH. Evolution of NADPH Oxidase Inhibitors: selectivity and mechanisms for target engagement. Antioxid Redox Signal 2015;23:406427. 